\title{
Successful staged management of neonatal midaortic syndrome
}

\author{
Jess L. Thompson, MD, ${ }^{\mathrm{a}}$ Katherine Sprouse, BS, ${ }^{\mathrm{a}}$ Arshid Mir, MD, ${ }^{\mathrm{b}}$ and Harold M. Burkhart, MD, \\ Oklahoma City, Okla
}

\footnotetext{
From the ${ }^{\mathrm{a} S e c t i o n}$ of Congenital Heart Surgery, Department of Surgery and ${ }^{\mathrm{b}}$ Section of Pediatric Cardiology, Department of Pediatrics, University of Oklahoma, Oklahoma City, Okla.

Disclosures: Authors have nothing to disclose with regard to commercial support.

Received for publication Aug 27, 2018; revisions received Nov 7, 2018; accepted for publication Nov 17, 2018; available ahead of print Jan 9, 2019.

Address for reprints: Jess L. Thompson, MD, 800 Stanton L. Young Blvd, Suite 9000, Oklahoma City, OK 73104 (E-mail: jess-thompson@ouhsc.edu).

J Thorac Cardiovasc Surg 2019; 157:e281-3

0022-5223/ $\$ 36.00$

Copyright $(\subset) 2018$ by The American Association for Thoracic Surgery https://doi.org/10.1016/j.jtcvs.2018.11.067
}

Midaortic syndrome (MAS) is narrowing of the descending thoracoabdominal aorta. Symptomatic MAS is associated with high mortality in neonates and infants. ${ }^{1}$ We describe the case of a 4-month-old infant with MAS and illustrate a staged, multidisciplinary, and multimodality approach.

\section{CASE REPORT}

A 4-month-old female infant was found to have dilated cardiomyopathy and severe left ventricular dysfunction. ${ }^{2}$ A blood pressure gradient of $70 \mathrm{~mm} \mathrm{Hg}$ was found between the upper and lower extremities. Computed tomography confirmed the diagnosis of MAS.

An initial strategy of cardiac catheterization was used to rehabilitate the aorta and improve distal perfusion. During the first catheterization at 4 months of age and a repetition at 8 months, the patient underwent placement of stents in the descending aorta (Figures 1 and 2). She had resolution of her left ventricular dilatation and dysfunction. When the patient was 2 years old, she had 2 additional stents placed. One year later, she underwent balloon angioplasty and dilation of the stents. Approximately 6 months after that, there was evidence of in-stent restenosis. Despite the in-stent stenosis, the patient had normal renal function, had diminished but present femoral pulses, and was gaining weight appropriately. She was then considered large enough for an adequately sized bypass conduit, so it was decided to operate. A midline laparotomy was performed, the bowl mobilized, and the infrarenal aorta exposed. Through a median sternotomy, the patient was placed on cardiopulmonary bypass through a cannula placed in the distal ascending aorta and a single venous cannula inserted into the right atrial appendage. Without arresting the heart, a side-biting clamp was place onto the ascending aorta. An 8-mm ringed GORE-TEX (W. L. Gore \& Associates, Inc, Medical Products Division, Flagstaff, Ariz) graft was then

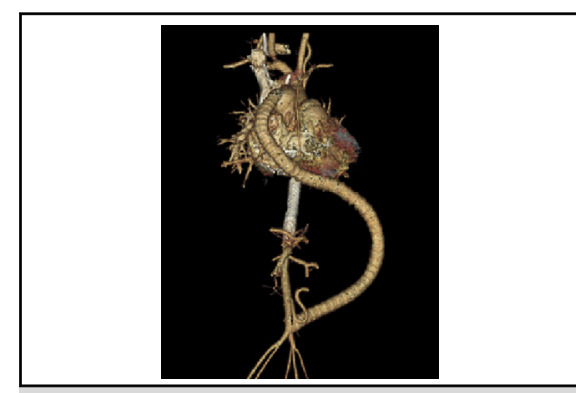

CT demonstrating 8-mm PTFE bypass graft of ascending aorta to descending aorta.

Central Message

We describe the unique presentation of a 4-monthold infant with midaortic syndrome and illustrate a favorable outcome achieved with a staged, multidisciplinary, and multimodality approach.

See Commentary on page e285.

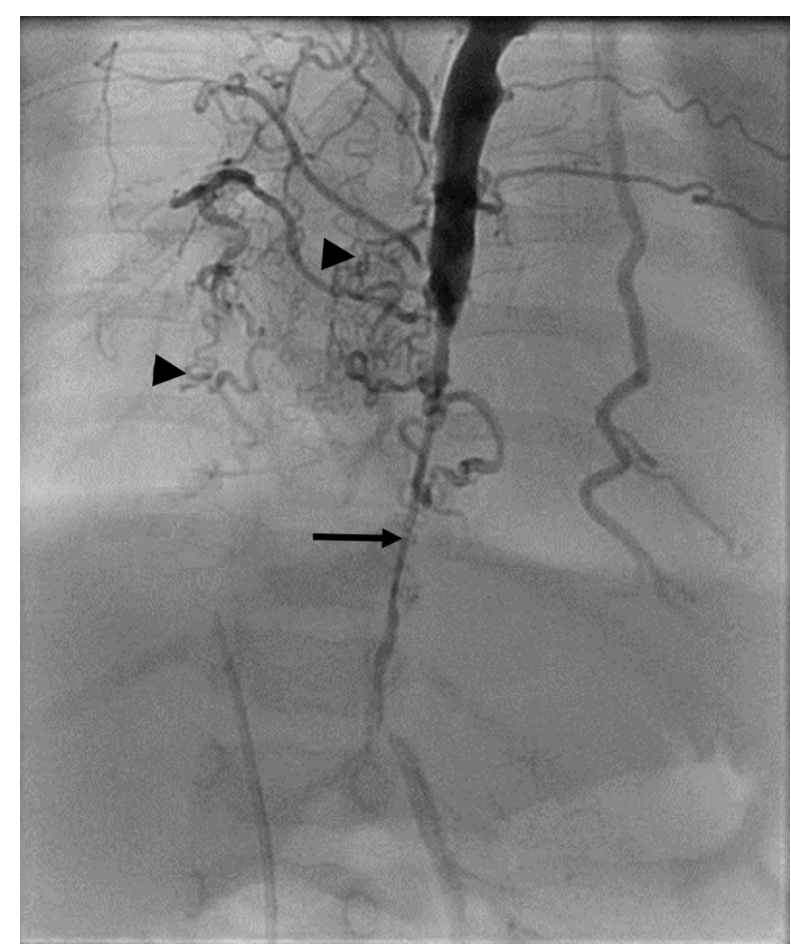

FIGURE 1. Aortic angiogram when the patient was 4 months old demonstrating the hypoplastic thoracic and abdominal aorta. The lumen of the descending aorta (arrow) measured $1.2 \mathrm{~mm}$. Multiple collateral vessels were noted (arrowheads). 


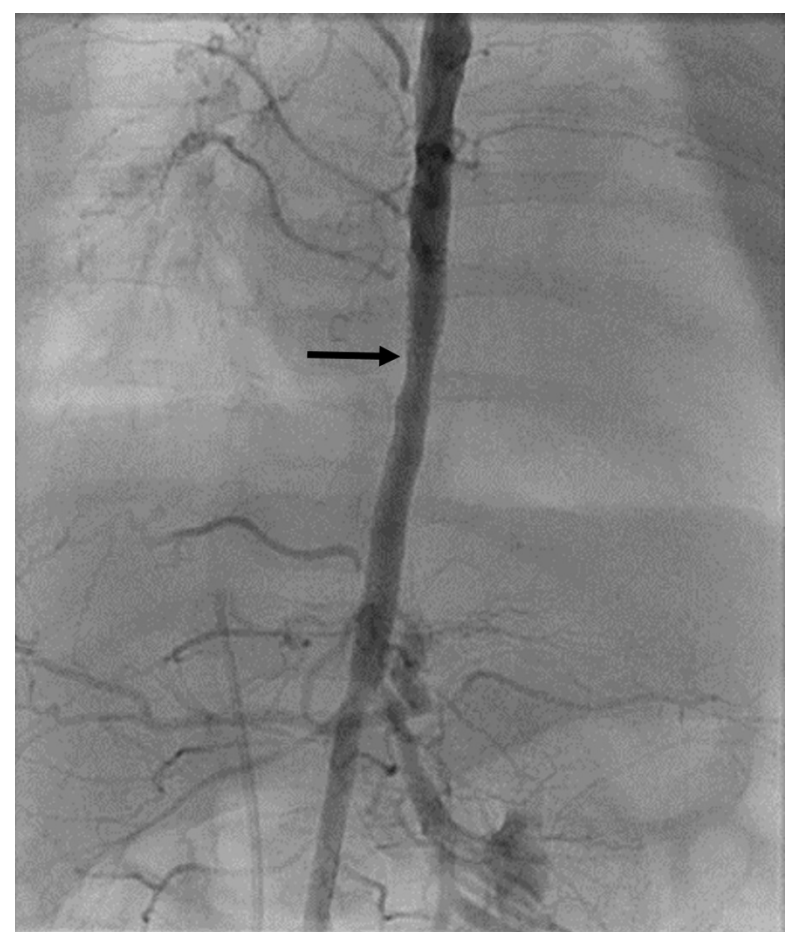

FIGURE 2. Aortic angiogram when the patient was 2 years old. After placement of overlapping stents in the distal thoracic and abdominal aorta (arrow) there was resolution of her left ventricular dilatation and normalization of left ventricular function.

anastomosed to the ascending aorta. The graft was deaired, and the patient was weaned from cardiopulmonary bypass.

The graft was placed lateral to the right atrium and then positioned intrapericardially along the diaphragmatic surface. The diaphragm was opened, and the graft passed through, posterior to the left hepatic lobe. The graft was left redundant, to allow for somatic growth. The 5-mm infrarenal aorta was controlled and opened. The end of the GORE-TEX graft was spatulated and sutured to the side of the aorta (Figure 3). The graft was then deaired, and the suture was secured. Simultaneous blood pressure measurements of the upper and lower extremities demonstrated that the mean blood pressures were equal.

Six months after surgery, the patient's blood pressure had normalized. She had normal biventricular function and a patent bypass graft.

\section{DISCUSSION}

Neonatal presentation of MAS is exceedingly rare and associated with a high mortality. ${ }^{1,3-5}$ Whereas coarctation of the aorta can present as congestive heart failure, dilated cardiomyopathy, as seen in our patient, is a rare presentation for MAS. ${ }^{6}$ Initial treatment for MAS is antihypertensive medication, followed by percutaneous therapies. Balloon angioplasty may reduce the integrity of the aorta, which could lead to aneurysm formation or rupture, and stenting is limited by restenosis.

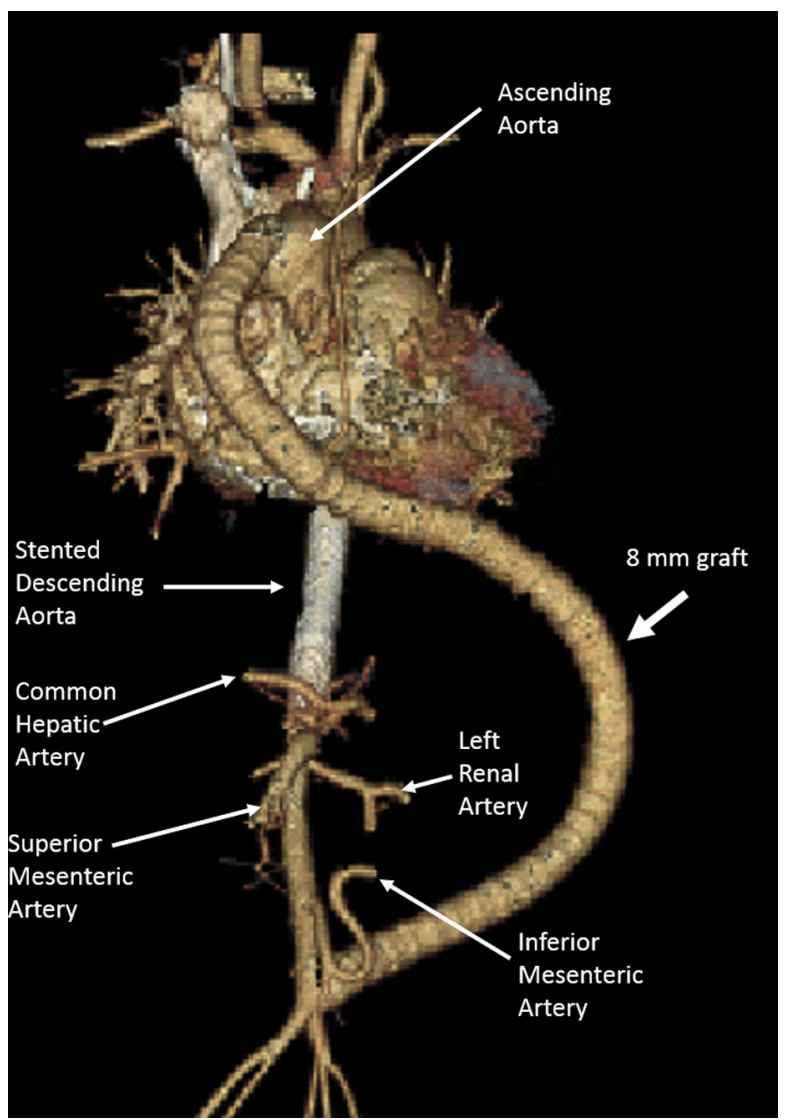

FIGURE 3. Computed tomography with contrast and 3-dimensional reconstruction of the chest and abdomen demonstrating the 8-mm GORE-TEX (W. L. Gore and Associates, Inc, Medical Products Division, Flagstaff, Ariz) ascending-to-descending aortic bypass graft and relevant vascular anatomy. The right renal artery was well visualized on other images.

The goal of surgical intervention for MAS is to restore blood flow to the distal aorta and its branches. Several surgical techniques have been reported, including bypass grafting aortic patch grafting, and an aortobifemoral bypass. ${ }^{2}$ All these surgical techniques have been fraught with disappointments.

The surgical approach used in our patient was an ascending-to-descending aortic bypass. The technique we used has been shown to be a simple solution to complex aortic coarctation. ${ }^{7}$ Similar to other groups, we have found that it is not as technically rigorous to perform the proximal anastomosis on the ascending aorta through a median sternotomy. ${ }^{8}$

\section{CONCLUSIONS}

Our case demonstrates the effectiveness of a staged, multidisciplinary, and multimodality management strategy to treat infants or children with symptomatic MAS. By initially rehabilitating the diminutive aorta with angioplasty 
and stenting, we were able to promote somatic growth, which ultimately allowed us to perform an ascending-todescending aortic bypass graft.

\section{References}

1. Das BB, Recto M, Shoemaker L, Mitchell M, Austin EH. Midaortic syndrome presenting as neonatal hypertension. Pediatr Cardiol. 2008;29: 1000-1.

2. Mir A, Stam B, Sperrazza C. A rare cause of cardiomyopathy in an infant: middle aortic syndrome. Cardiol Young. 2017;27:794-6.

3. Gospin TA, Knudson JD, Petit CJ. Neonatal midaortic syndrome and renal artery atresia presenting as malignant hypertension. Pediatr Cardiol. 2012;33:869-71.
4. Terramani TT, Salim A, Hood DB, Rowe VL, Weaver FA. Hypoplasia of the descending thoracic and abdominal aorta: a report of two cases and review of the literature. J Vasc Surg. 2002;36:844-8.

5. Zeltser I, Parness IA, Ko H, Holzman IR, Kamenir SA. Midaortic syndrome in the fetus and premature newborn: a new etiology of nonimmune hydrops fetalis and reversible fetal cardiomyopathy. Pediatrics. 2003;111:1437-42.

6. Hwang MS, Chu JJ, Chang YS, Su WJ. Dilated cardiomyopathy: an unusual presentation of aortic coarctation in an infant. Cardiology. 2006;106:56-8.

7. Said SM, Burkhart HM, Dearani JA, Connolly HM, Schaff HV. Ascending-to-descending aortic bypass: a simple solution to a complex problem. Ann Thorac Surg. 2014;97:2041-7; discussion 2047-8.

8. Hetzer R, Absi D, Miera O, Solowjowa N, Schulz A, Javier MF, et al. Extraanatomic bypass technique for the treatment of midaortic syndrome in children. Ann Thorac Surg. 2013;96:183-9. 